\title{
THE ASSESSMENT OF LANDSCAPE AND ENVIRONMENTAL RISKS AND HAZARDS CAUSED BY LANDSLIDES IN MOUNTAIN AREAS
}

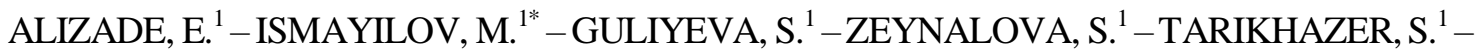 \\ YUNUSOV, M. $^{1}-$ MUSTAFAYEV, ${ }^{1}{ }^{1}-$ MAMMADBAYOV, E. ${ }^{1}$ \\ ${ }^{1}$ Institute of Geography named after acad. H. Aliyev, Azerbaijan National Academy of Sciences, \\ 115, av. H.Cavid, Baku, Azerbaijan \\ (phone: +994 505416430) \\ *Corresponding author \\ e-mail: elgeom@mail.ru \\ (Received $28^{\text {th }}$ Nov 2015; accepted $12^{\text {th }}$ May 2016)
}

\begin{abstract}
The landslide is a kind of natural disaster responsible for creation of risks and hazards in relation to population and its economic activity. Each year the occurrence of landslides causes killing of people and economic losses, as well as leads to destruction and deterioration of pastures, arable lands, forests and highways. The southeastern slope of Greater Caucasus is one of the most active landslide zones in Azerbaijan. As a result of the occurrence of landslide in the Mughanli area in 2011, 168 houses out of 279 ones became unusable while the village of the same name was moved to a new residential area. Moreover, the $3 \mathrm{~km}$-long part of the Ismayilli-Mughanli-Shamakhi highway near the village became unusable repeatedly. In 2014, USD 52 million was spent in order to eliminate the consequences of landslides. Topographic maps of scale of 1:10000 and also aerospace images were used to assess the landscape- and environmental risks and hazards caused by landslides. Maps of various factors of the same scales, compiled in ArcGIS program were analysed through GIS technologies, which allowed compilation of a map of relevant landscape- and environmental risks and hazards. The carried out studies will enable to estimate natural disasters and reduce the related economic losses.
\end{abstract}

Keywords: environmental, landslide, morphodynamic, natural disasters, economic losses

\section{Introduction}

In recent years, mountain geosystems were under the influence of considerable anthropogenic load, driven by such factors as the rapid development of new settlements, the laying of new asphalted motorways, the construction of industrial facilities as well as the development of mining industry. In this regard, the investigation of landscapeand geomorphological processes, posing a hazard to the sustainable development of the natural-economic systems in the mountainous areas, as well as the forecasting and the prevention of this processes are regarded as topical issues. High seismicity in the southeastern part of the Greater Caucasus favourably affects the occurrence of morphodynamic processes, including the landslides. The preliminary assessment of hazards and risks posed by landslides in the mountain areas through the application of up-date methods may prevent or reduce damage.

This work has been carried out due to financial assistance of the Science Development Fund under the President of the Republic of Azerbaijan (Grant No. EIF2012-2(6)-39/15/2).

The carried out studies regarding the grade of landslide-related risks and hazards reveal that the growth of factors increases the level of accuracy and reliability of results (Lee, 2005; Wang et al., 2009). 


\section{Material and methods}

\section{Study Area}

The study area covers the intensive areas of Azerbaijan in terms of occurrence and spread of landslide, namely the southeastern slope of Greater Caucasus Mountains where Mughanli village and part of Nuran village, as well as the municipalities of Shirvanzadeh and Mirikend are located. Population and the economic activities in the mentioned settlements suffer from landslides periodically. The study area is situated on the $41^{\circ} 53^{\prime}$ north latitude and $49^{\circ} 33^{\prime}$ east longitude. The territory area makes up 1057,5 hectares. The area typically has low relief and hilly terrains with the maximum height of $1214 \mathrm{~m}$ and the lowest point at $326 \mathrm{~m}$. This mountainous territory is densely populated compared to its surrounding areas (Fig. 1).

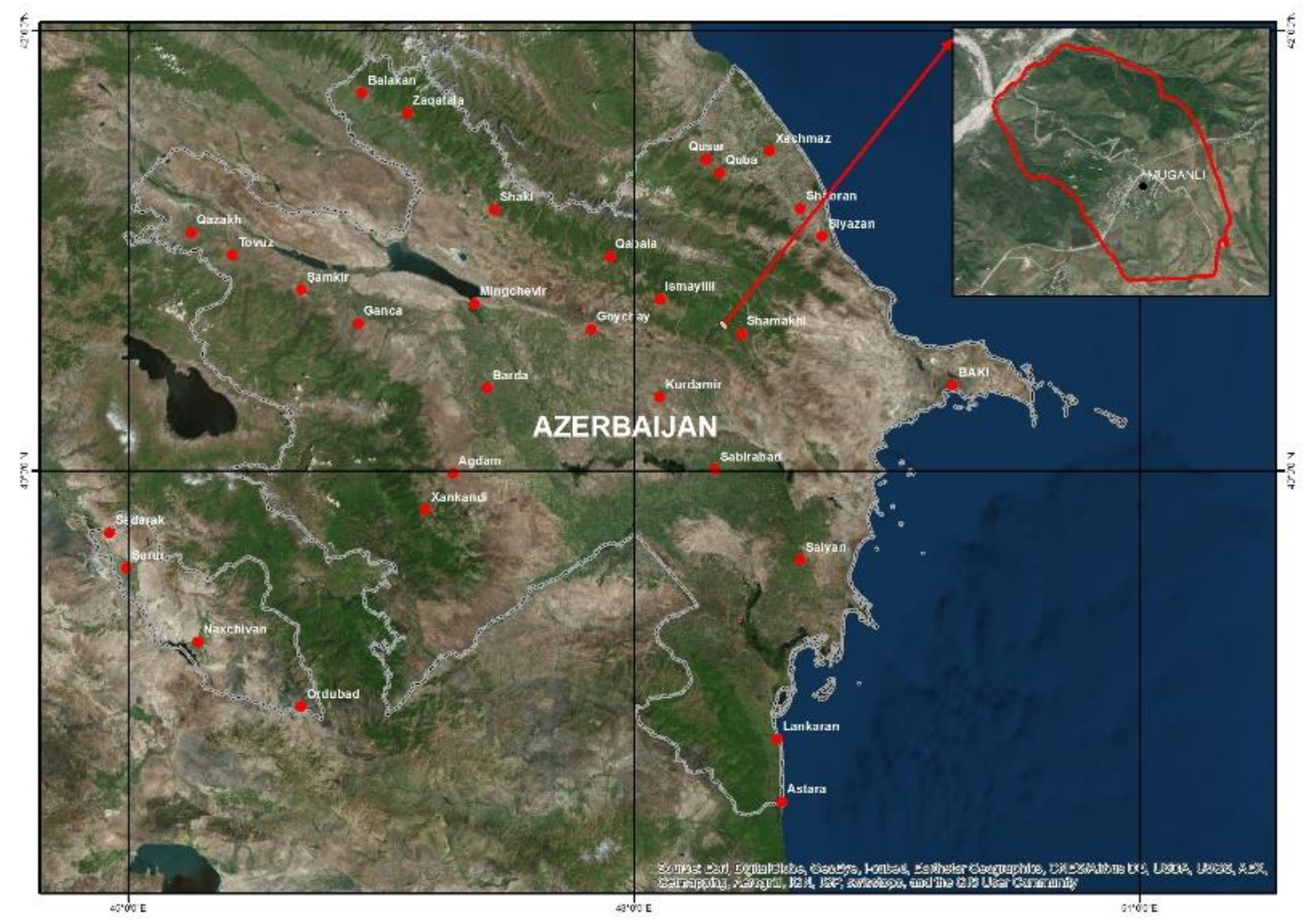

Figure 1. Location of the study area

\section{Methodological approaches}

In order to increase the extent of accuracy and reliability of the determination of level of landslide-related risk and hazard, ArcGIS/ArcMap programs and GIS were applied. Landslide risk model based on GIS (Lee, 2005; Wang et al., 2009; Mora et al., 1994; Varner, 1984; Griffiths et al., 2008) as well as related investigations (Kumtepe et al., 2011) were used in the work. The assessment and modelling of level of landslide risk and hazard along with the compiling of relevant maps will allow to increase the efficiency of mastering of territory and apply the landscape planning properly. Such 
maps will contribute to minimize and eliminate losses caused by landslides that may occur in the future.

The GIS-based landslide risk model of Mora et al. (1994) was used. The reasons of occurrence of landslides are classified in the above mentioned studies. The first group of reasons includes are the main reasons of while the second group takes are responsible for the activation of landslides. The morphometric parameters of relief along with the lithological composition of rocks and the soil moisture index are listed as the main reasons of landslides, while the average perennial precipitation and seismicity were considered as activating factors. The factors were analysed through GIS in accordance with the following formula:

$$
\mathrm{A}(\mathrm{fet})_{\text {landslide }}=\left(\mathrm{S}_{\mathrm{d} \times} \mathrm{S}_{\mathrm{lc}} \times \mathrm{S}_{\mathrm{sm}}\right) \times\left(\mathrm{T}_{\mathrm{al}}+\mathrm{T}_{\mathrm{sr}}\right)
$$

where $S_{d}$ is the degree of inclination of slopes; $S_{\text {lc }}$ is the lithological composition of rocks; $\mathrm{S}_{\mathrm{sm}}$ is soil moisture index; $\mathrm{T}_{\mathrm{al}}$ is the average monthly amount of precipitation in multiyear period; and $\mathrm{T}_{\mathrm{sr}}$ is the seismicity rate.

Kumpete et al. (2011) used eight indicators to assess the extent of landslide-related hazard: inclination of a slope, direction of a slope, curvature of a slope, index of plant cover, lithological composition of rocks, tectonic fracture, farness in relation to rivers and roads. Landscape- and environmental risks of landslides were identified with taking into account the specific characteristics of the studied southeastern slope of Greater Caucasus as well as such factors as anthropogenic loading, land use, relief, vertical and horizontal fragmentation, indices of landscape's ecomorphological tensity and factors of landscape- and environmental assessment. Relatedly, the following formula was used:

$$
S_{i}=\frac{\sum S}{\sum S_{f i c}}: N
$$

where $S_{i}$ is the landslide intensity index; $S$ is the area affected by landslides; $S_{\text {fic }}$ is the total area of factors, involved to the comparison; and $\mathrm{N}$ is the number of measurements.

The figures of landslide intensity index obtained due to calculations are ranked as follows: <0,1 -very weak; 0,1-0,3 - weak; 0,3-0,5 - middle; 0,6-0,8 - high; >0,8 very high. Researchers note that the correlation between the indicator of landslide intensity index and the level of landslide-related risk and hazard is available (Varner, 1984). The landslide intensity index was identified by each factor responsible for the activation of landslide. Then the gained data was analysed through GIS. The last phase of was carried out based on the following formula:

$$
S_{i}=\frac{S_{a}+S_{l}+S_{v t}+S_{i}+S_{e}+S_{s i}+S_{s d}+S_{v c}+S_{l c}+S_{t f}+S_{d r}+S_{e b}}{S_{f i c}}
$$


where $S_{a}$ is the anthropogenic loading; $S_{1}$ is the use of lands; $S_{v f}$ is the vertical fragmentation of relief; $S_{\mathrm{e}}$ is the eco-geomorphological tension; $S_{\mathrm{si}}$ is the inclination of slope; $S_{\mathrm{sd}}$ is the direction of slope; $S_{\mathrm{sc}}$ is the curvature of slope; $S_{\mathrm{vc}}$ is the vegetation cover; $S_{\mathrm{lc}}$ is the lithological composition of the rocks; $S_{\mathrm{tf}}$ is the tectonic fracture; $S_{\mathrm{dr}}$ is the distance from rivers; $S_{d r}$ is the distance from roads; and $S_{e b}$ is the environmental balance.

\section{Results}

\section{Tectonic fault}

The purpose is to determine the relation between soil use, coefficient of vegetation cover and also environmental and landscape balance (I) and the intensity coefficient of landslide as well as the level of risk and hazard (II). Active landslides in the study area are mapped, and are grouped by five levels in accordance with the risk and hazard, on the basis of which, the conducted assessment is expressed by five points (Fig. 2).

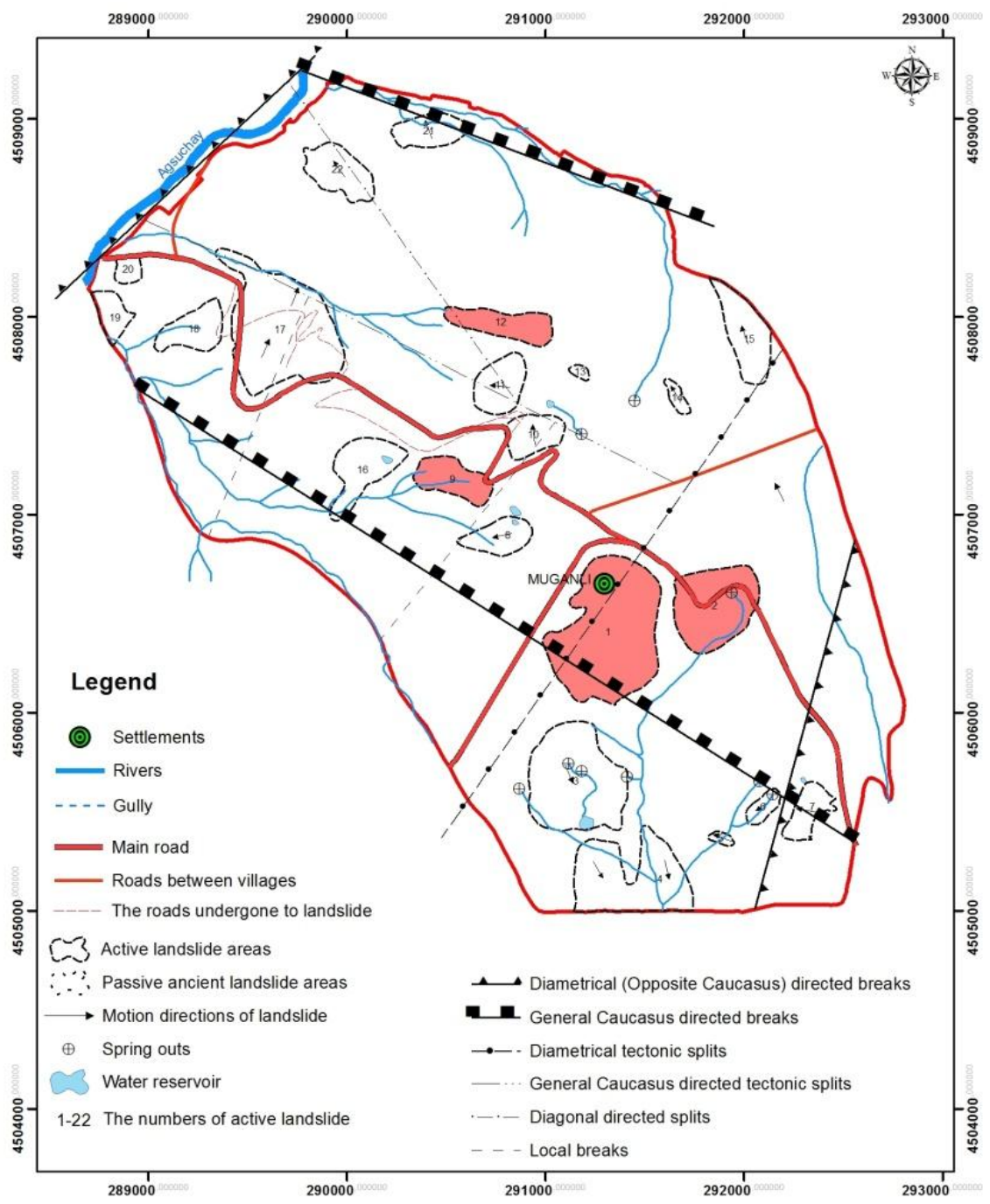

Figure 2. Prevalence of active landslide areas and tectonic faults 


\section{The assessment of the impact of soil use on the risk level and dynamic of landslides}

The use of land as one of forms of anthropogenic activity is regarded as an important factor of assessment of risk and hazard posed by landslide (Ismayilov et al., 2012). Researches show that landslides may happen at very different extent depending on agricultural activities, perennial plant-growing, gardening, pasturing, settlements' impact, the availability of roads and communications, etc. (Fig. 3).

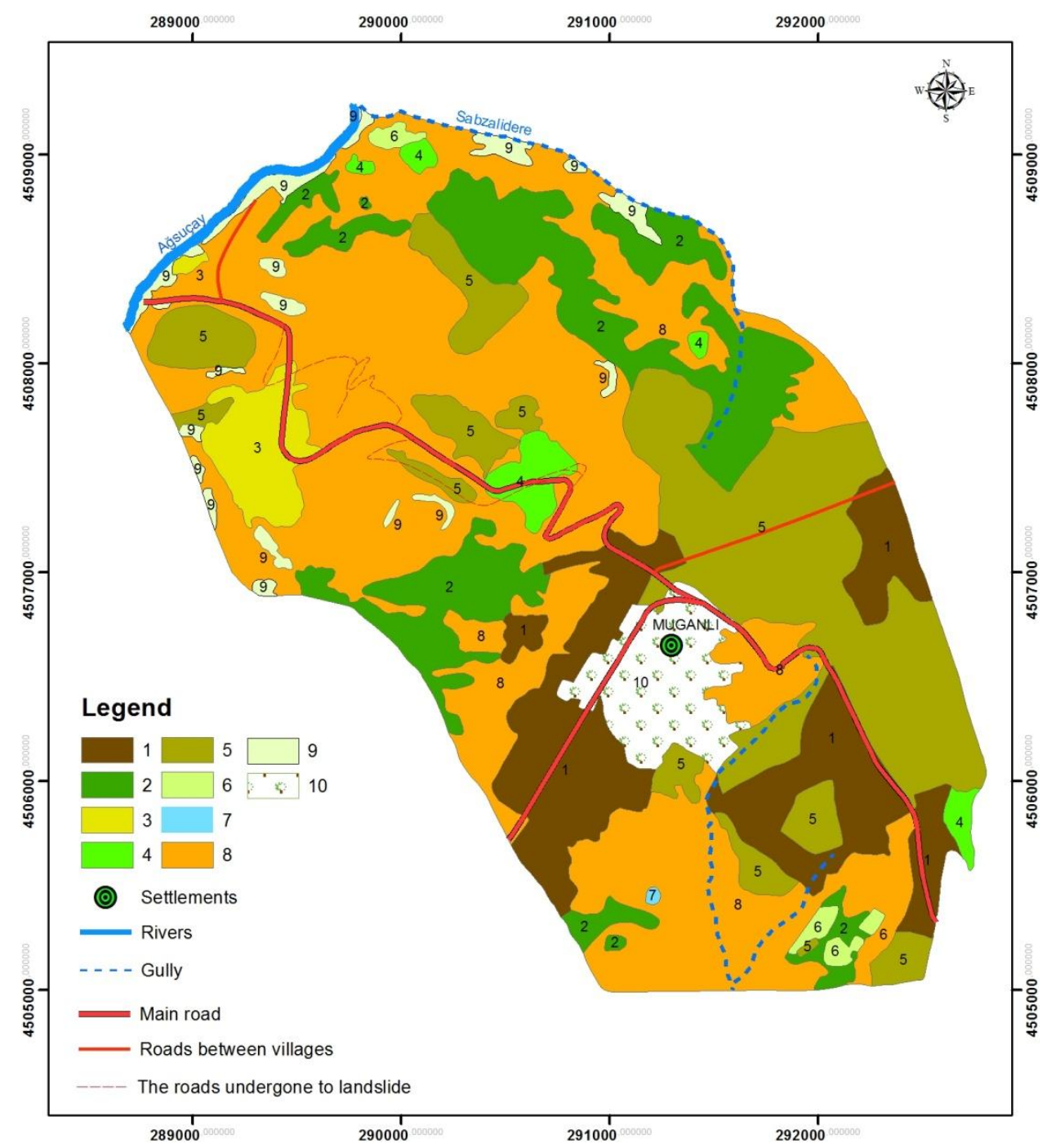

Figure 3. Impact of soil use on the landslides.

The map legend reflects the impact of soil use on the occurrence of landslides in the municipality of Mughanli and surrounding areas: 1. Plantations of perennial plant-growing - medium hazard of landslide. 2. Rare trees and shrubs used in pasturing - medium hazard of landslide. 3. Shrubberies and meadows composed of small bushes and used as pastures and hayfields - very high hazard of landslide. 4. Woodlands, partially used in pasturing and anthropogenically degraded - low hazard of landslide. 5. Arable or fallow lands of low-incline watershed areas - very weak hazard of landslide. 6. Fruit gardens, composed of perennial plants - weak hazard of landslide. 7. Artificial water reservoirs - very high hazard of landslide. 8. Pastures and hayfields on low-incline slopes - high hazard of landslide. 9. Cliffs and sandy areas, not usable in agriculture - very low hazard of landslide. 10. Rebuilt settlements, courtyards and roads - very high hazard of landslide. 
The analysis of electronically compiled maps (1:10000), reflecting the land use in the Mughanli municipality and surrounding areas shows that the most part of the lands $(42,1 \%)$ is occupied by pastures and hayfields of low-incline slopes, while $20,4 \%$ is composed of ploughed arable and fallow lands; $13,0 \%$ is composed of rare trees and shrubberies used in pasturing; $12,9 \%$ is composed of perennial plants and plantations; $4,4 \%$ is composed of rebuilt settlements, courtyards and roads; $2,7 \%$ is composed of shrubberies and meadows with small bushes usable in pasturing; $2,1 \%$ is composed of cliffs and sandy areas, unusable in agriculture; and $1,8 \%$ is composed of woodlands, weakly degraded due to anthropogenic factors. Fruit gardens, composed of perennial plants as well as artificial water reservoirs occupy very small area.

In order to increase the extent of accuracy and confidence of spread of landslides, ArcGIS program was applied. Furthermore, the relations between the land use and the intensity of landslides as well as related risks and hazards were studied and given on Table 1.

Table 1. The relations between land use and risks, hazards and intensity of landslides in the study area

\begin{tabular}{|c|c|c|c|c|c|c|}
\hline $\begin{array}{c}\text { Land } \\
\text { use } \\
\text { form }\end{array}$ & Contours & Area, $\mathrm{m}^{2}$ & Area, \% & $\begin{array}{c}\text { Areas affected } \\
\text { by landslide, } \mathrm{m}^{2}\end{array}$ & $\begin{array}{c}\text { Intensity index of } \\
\text { landslide }\end{array}$ & $\begin{array}{c}\text { Risk of } \\
\text { landslide } \\
\text { by point }\end{array}$ \\
\hline 1 & 5 & 1363317,38 & 12,89333 & 408995,15 & $0,3-0,5$ & 3 \\
\hline 2 & 9 & 1372456,849 & 12,97977 & 411737,04 & $0,3-0,5$ & 3 \\
\hline 3 & 2 & 282397,8519 & 2,670728 & 169438,74 & $0,6-0,8$ & 4 \\
\hline 4 & 5 & 185242,5323 & 1,751898 & 18524,25 & $0,1-0,3$ & 1 \\
\hline 5 & 12 & 2155254,285 & 20,38294 & 215525,43 & 0,1 and lesser & 1 \\
\hline 6 & 4 & 71388,13235 & 0,675141 & 7138,813 & 0,1 and lesser & 2 \\
\hline 7 & 1 & 4891,499597 & 0,046261 & 3913,1996 & 0,8 and higher & 5 \\
\hline 8 & 5 & 4455169,254 & 42,13398 & 356135,41 & $0,6-0,8$ & 5 \\
\hline 9 & 17 & 223933,4774 & 2,117812 & 11196,74 & $0,3-0,5$ & 4 \\
\hline 10 & 1 & 459764,8675 & 4,348146 & 367811,97 & 0,8 and higher & 5 \\
\hline
\end{tabular}

The analysis of the Table 1 shows that the pastures and hayfields (4 and 5 scores) as well as the areas of rebuilt settlements, courtyards and roads along with the areas near the artificial reservoirs have high (5 scores) and very high landslide risks. Such approach reveals that $51,4 \%$ of the study area has high or very high risk of landslide.

\section{The assessment of impact of vegetation cover indexes on the dynamics of landslides and the risk level.}

The compiling of maps of vegetation cover of the study area has been justified by some researchers engaged in the study of landslide dynamics and the related risk level (Kumtepe et al., 2011). The analysis of old topographic and vegetation maps and also aerospace photos, taken in different years along with the surveys held among the elder population contributed to the conduction of researches on 
reasons and results of relations between the intensity of landslides and the vegetation cover during the last 100-110 years. The researches revealed that in the past the vegetation of this territory was presented by arid and semi-arid forests and shrubs. The forests were composed mostly of drought-resistant Georgian oak (Quercus L.), elm (Ulmus L.), the hornbeam (Carpinis L.), juniper (Yuniperus L.), pears (Prus), Caucasian olive (Elaeagnus L.), Iberian tree (Aser L.), hawthorn etc. In the following periods, these forests faced heavy adverse impact and were converted to various vineyards, orchards and pastures. The deep root system of drought-resistant trees and shrubs of those arid forests were increasing the resistance of natural complexes in regard to exogenous geomorphological processes. The transformation of arid forests into anthropogenic complexes in the $80 \mathrm{~s}$ of $20^{\text {th }}$ century as a result of the implementation of government programs has entailed the intensification of landslides. Eventually, in 1982, about 20 houses of the village of Mughanli were almost destrcuted by this natural disaster. The second phase of activation of landslides in Mughanli and surrounding areas was observed in 2010 and following years. This happened due to the massive deforestation, conducted in 1992-2008 years, and was driven by the demand for firewood in the villages. More than 100 houses became unusable during the second phase of activation of the Mughanli landslide (Fig. 4).

The analysis of contemporary vegetation map (1:10000) indicates that $10,2 \%$ of the study area consists of anthropogenically violated derivative forests, while out of the remaining, $6,4 \%$ is mixture of forests and bushes, $37,3 \%$ are shrubby meadows, 24,2\% are cereals and other cultivated plants, and 8,9\% are courtyard areas consisting of cultivated plants (Fig. 3). The analysis of the maps of vegetation and landslide intensity in ArcGIS (Fig. 3 and Table 2) reveals that $58,6 \%$ of the study area is high or very high hazardous in terms of occurrence of landslides, while $6,4 \%$ is the area is of medium hazard, $10,2 \%$ of low hazard and $24,7 \%$ of lesser hazard.

Table 2. Distribution of vegetation coverage according to risk and hazard intensity indexes of landslide areas

\begin{tabular}{|c|c|c|c|c|c|c|}
\hline $\begin{array}{c}\text { Number } \\
\text { of plant } \\
\text { group } \\
\text { on the } \\
\text { map }\end{array}$ & $\begin{array}{c}\text { Quantity of } \\
\text { contours }\end{array}$ & Area, $\mathrm{m}^{2}$ & $\begin{array}{c}\text { Areas affected } \\
\text { by landslide, } \mathrm{m}^{2}\end{array}$ & Area, \% & $\begin{array}{c}\text { Intensity index } \\
\text { of landslide }\end{array}$ & $\begin{array}{c}\text { Risk of } \\
\text { landslide } \\
\text { by point }\end{array}$ \\
\hline 1 & 10 & 1082116,302 & 324634,79 & 10,179 & $0,1-0,3$ & 2 \\
\hline 2 & 5 & 2582968,086 & 258296,8086 & 24,29686 & 0,1 and lesser & 1 \\
\hline 3 & 3 & 45969,51975 & 4596,951975 & 0,432415 & 0,1 and lesser & 1 \\
\hline 4 & 6 & 3963562,311 & 2378137,3866 & 37,28351 & $0,6-0,8$ & 4 \\
\hline 5 & 7 & 681243,8121 & 204373,14363 & 6,408166 & $0,3-0,5$ & 3 \\
\hline 6 & 12 & 997977,0763 & 598786,24578 & 9,387539 & $0,6-0,8$ & 4 \\
\hline 7 & 2 & 177842,3607 & 142273,88856 & 1,672887 & 0,8 and higher & 5 \\
\hline 8 & 11 & 151173,1914 & 120938,55312 & 1,422021 & 0,8 and higher & 5 \\
\hline 9 & 2 & 948017,9514 & 568810,77084 & 8,917596 & $0,6-0,8$ & 4 \\
\hline
\end{tabular}




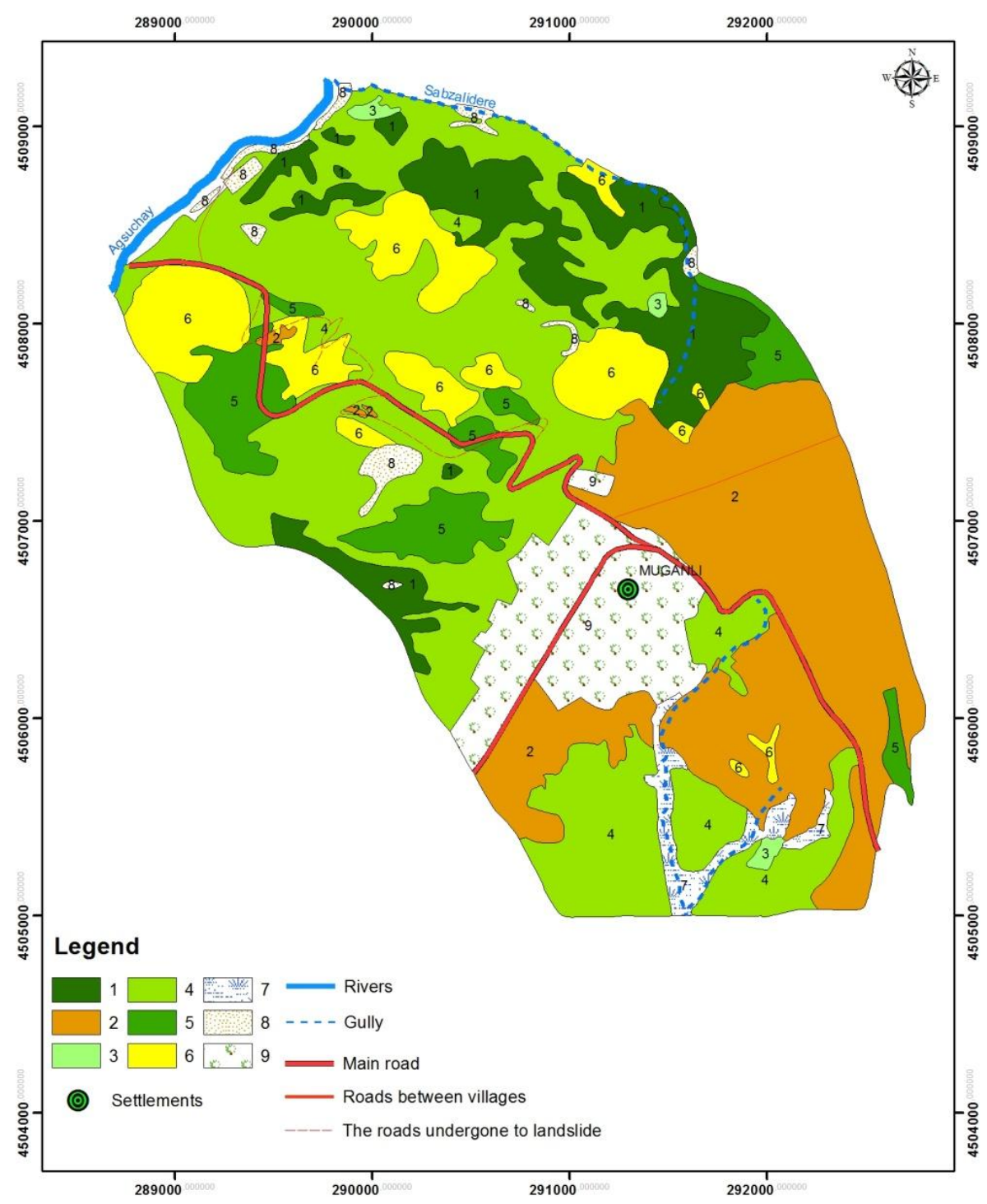

Figure 4. The impact of the extent of vegetation cover on landslides.

The legend of the map, reflecting the impact of vegetation cover on landslides includes: 1. Forests damaged due to anthropogenic impacts and composed of trees of lesser height $(2-4 \mathrm{~m})$ and low density such as Oriental beech (Fagus L), Georgian oak (Querkus L.), Caucasian hornbeam (Carpinus L.), elm (Ulmus L), hawthorn (Crataequs L.), medlar (Mespilus L.), etc. 2. Crops, like wheat, oats, barley, corn, grapes, etc. 3. Fruit gardens and perennially growing shrubberies. 4. Shrubberies and grasslands, composed of blackthorn (Paliurus spina Christi), buckthorn (rhamnus L), etc. 5. Forests and shrubberies, reduced in density due to anthropogenic impact. 6. Meadow- and steppe vegetation, composed of thorny plants (spiana, asantha, murex), cereals (Gramieak) and various mountain steppes (Valliherbetum). 7. Reedy plants; wetland meadows and pastures; sparse and low trees and bushes. 8. Sandy, rocky, stony areas and steep slopes without vegetation. 9. Courtyards, consisting of cultivated plants.

\section{Assessment of landscape- and environmental risks and hazards caused by the landscape landslides}

In order to assess landscape- and environmental risks and hazards, posed by landslides in the study area, the existing areals of landslides were compared with the maps of land use (I), extent of vegetation cover (II) and also landscape and environment (III) of large scale (1:10000). Based on this comparison and the above-mentioned 
formula, the intensity indexes of spread of active landslides through ArcGIS program were measured. This enabled compile the map of landscape-and environmental risks and hazards caused by landslides in the study area (Fig. 5).

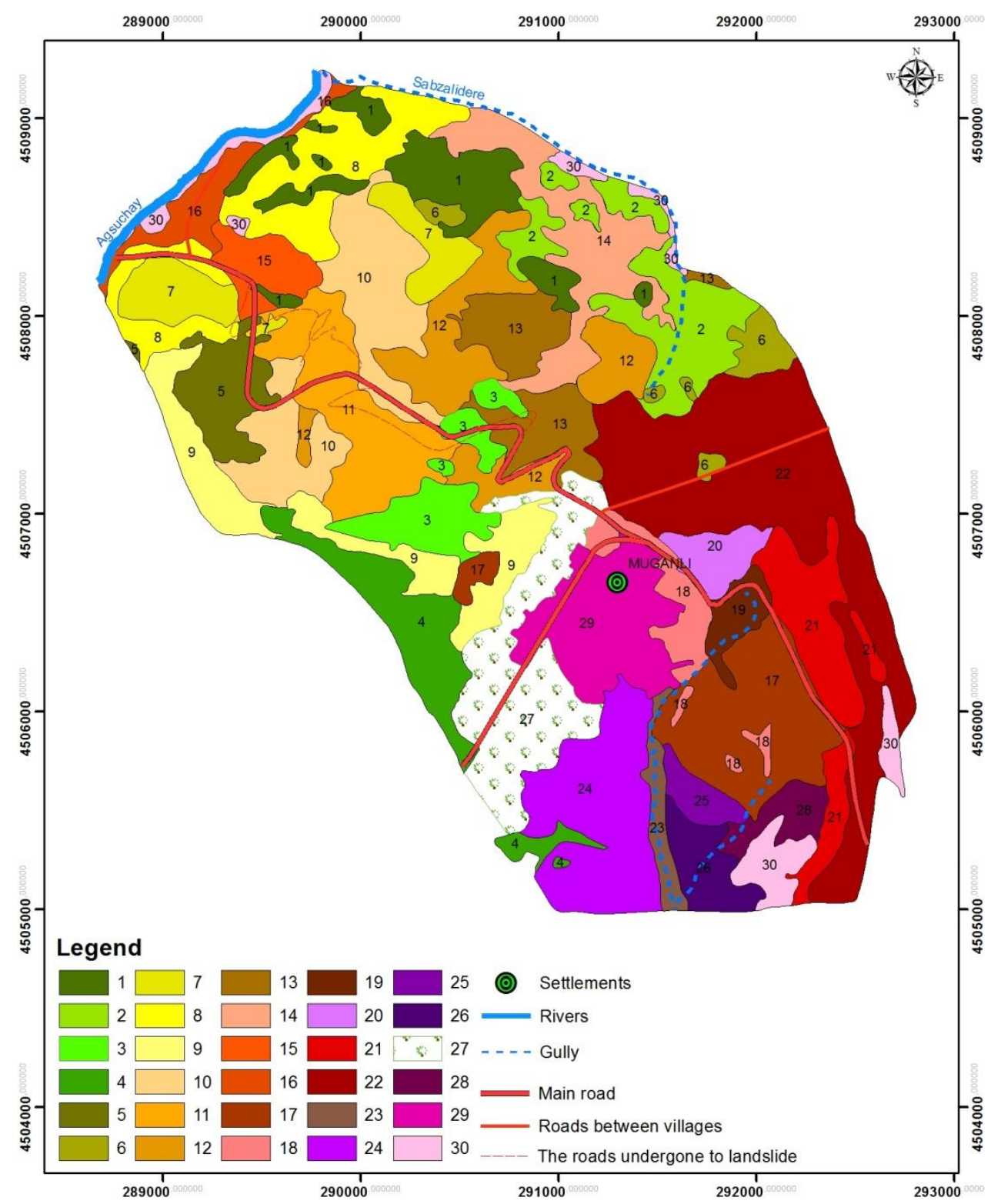

Figure 5. Landscape and environmental risks and hazards caused by landslides. The legend of map of landscape- and environmental risks and hazards caused by landslides:

I. Landscapes of mountainous forests in low mountain areas. 1. Secondary forests, composed of oak and hornbeam and widespread over brown forest soils of highly shattered slopes of medium hazard of sliding; and shrubs grown under forests $\left(25^{\circ}-35^{\circ}\right.$ of inclination). 2. Secondary sparse arid forests, composed of hornbeam, elm, oak, hawthorn, hips, buckthorn, etc. and spread over brown mountain soils on slopes, shattered at medium extent, with medium hazard of sliding $\left(20^{\circ}-25^{\circ}\right.$ of inclination). 3. Trees and shrubs like elm, hornbeam, hawthorn, blackthorn, etc. widespread on brown forest soils of slopes with wavy surface, shattered at medium extent, with very high hazard of sliding $\left(25^{\circ}-35^{\circ}\right.$ of inclination).

II. Landscapes of secondary forest and bush in low mountain areas: 4. Secondary meadows, bushes, pastures and hayfields, covering brown forest soils of extremely shattered and wavy south-western slopes with medium hazard of sliding $\left(25^{\circ}-35^{\circ}\right.$ of inclination). 5. Forest bushes, covering light brown and partially carbonate soils on hilly and highly shattered slopes of medium hazard of sliding $\left(20^{\circ}-35^{\circ}\right.$ of inclination). 
III. Landscapes of shrubby meadows and steppes in low mountain areas. 6. Meadow bushes, separate trees and pastures, spread over light brown, blackish and carbonate forest soils of slightly shattered south-western and north-western slopes of with high hazard of sliding $\left(20^{\circ}-25^{\circ}\right.$ of inclination). 7. Complexes of field and garden, composed of sparse blackthorn, blackberry, grasses etc. on slightly carbonate brown soils of smooth and weakly shattered watershed areas with less hazard of sliding $\left(5-10^{\circ}\right.$ of inclination). 8. Cereals, clovers, sparse shrubs, growing over brown carbonate mountain forest soils of highly shattered and eroded steep slopes with very high hazard of sliding (30-35 of inclination). 9. Arid forests and shrubs of blackthorn, buckthorn, sparse oak, elm, etc. spread over dark-brown mountain forest soils of lower mountain slopes, shattered at medium extent; with high hazard of sliding. 10. Postforest steppe plants, pastures and hayfields on brown forest soils of slopes, shattered at medium extent and affected by ancient landslides; with medium hazard of sliding. 11. Post-forest shrubberies, spread on mountain forest soils of western slopes; shattered at medium extent; with high hazard of sliding. 12. Mogpog, oat, various shrubs, etc., spread on brown mountain forest soils of weakly shattered slopes with medium hazard of sliding. 13. Hawthorn, blackberry, blackthorn and various kinds of grasses, covering slightly carbonate brown soils of averagely shattered mountain slopes, violated due to anthropogenic impact; with very high hazard of sliding. 14. Cereals and shrubberies, spread on brown and also dark chestnut soils of western and southwestern slopes with wavy surface shaped in post-forest areas and shattered considerably; with high hazard of sliding (25 of inclination). 15. Various grasses and sparse shrubs spread on brown soils of weakly shattered slopes of dry river valleys, with very high hazard of sliding. 16. Anthropogenically violated grassland shrubberies, spread on meadow soils of accumulative and weakly shattered river terraces, safe in terms of sliding. 17. Various grasses, cereals and partially vineyards, spread on dark-chestnut and blackish soils of weakly shattered, smooth and a little wavy watershed areas of lesser hazard of sliding. 18. Grassland and steppe vegetation, pastures and hayfields on brown- and meadow soils of eastern and southeastern slopes of medium hazard of sliding. 19. Postforest mountain steppes covering brown- and meadow soils of valleys with waterlogged bottom and of high hazard of sliding. 20. Various herbs, clovers and bushes, spread on brown soils of low-incline and wavy mountain slopes of very high hazard of sliding. 21. Pastures, widespread in weakly shattered and less-incline smooth watersheds of low hazard of sliding. 22. Sparse shrubberies, pastures and hayfields, spread on brown mountain soils of slopes of high hazard of sliding (20-25 of inclination). 23. Vegetation, presented by poplar, elm, blackberry and etc. on brown meadow soils of dry river valleys. 24. Grasslands and steppes with sparse shrubberies covering eroded brown soils of ancient southern, southeastern and south-western slopes of very high hazard of sliding. 25. Various herbs, cereals and mostly pastures covering blackish and light chestnut soils of slopes of smooth watershed with less hazard of sliding. 26. Post-forest shrubberies, meadows and steppes, spread on brown mountain soils of weakly shattered watershed with smooth and less-incline surface (5-6 $6^{\circ}$. 27. Orchards and vineyards covering brown forest soils in weakly fragmented southwestern watershed with smooth surface; with hazard of sliding at medium extent. 28. Reeds, shrubberies and tall grasses covering brown meadow soils of expanded dry valleys. 29. Sandy areas with poor soil cover in accumulative river valleys. 30. Landscapes of residential areas of low-incline and smooth watersheds of active hazard of sliding.

Results of environmental risks and hazards are grouped as reflected in Table 3. Analysis of this table shows that 55,9\% of the territory is of high and very high hazard of sliding. Based on the map, natural complexes were grouped in 5 classes. 1. Landscapes of very high hazards. 2. Landscapes of high hazard. 3. Hazardous landscapes. 4. Landscapes of low hazard. 5. Landscapes of very low hazard.

As Figure 3 reflects, the landscapes of high and very high hazard of sliding are covering landscape-and environmental facies, numbered as 3, 6, 8, 9, 11, 12, 15, 19, 20 and 30, the area of which makes up 55,9\% the overall territory of the study area. These areals consist of mostly ellevial and delluvial sediments, clayey, allevrolit and limestone rocks, and encompass mainly the western, south-western, north-western and northern slopes. The vegetation coefficient is less than 1 and is represented by complexes of very rare forests and bushes, shrubberies and shrubby meadows, violated due to anthropogenic impact. These areas are used mostly as pastures and hayfields, and partially as planting areas, residential houses, courtyards and networks of highway and 
communication. The seismicity reaches 8-9 points. The implementation of serious measures against landslides is needed in this landscape-environmental facies. Namely, the grazing norm should be followed properly, whereas the planting of trees and shrubs adapted to local environmental conditions is needed as well. Beside with this, the regulation of surface waters, as well as the improvement of regime of underground waters through the establishment of vertical and horizontal system of drainage should be managed. Anthropogenic loading must comply with environmental norms.

$29,1 \%$ of the study area is composed of the landscapes of medium hazard of sliding. As the analysis of environmental risks and hazards indicates, contours numbered as 1,2, 5, 10, 12, 14, 18 and 27 (Fig. 4) are listed in this class. Slopes, typically of 10-15 and over of inclination in some cases are very complicated due to the influence of ancient landslides. Inclination of some slopes equates $5-6^{\circ}$. Rocks of high hazard of sliding like clay, shale, marl, sand, sandstone, lime are widely found. The vegetation cover coefficient of the area is about 1 , while the flora is represented by derivative forests, consisting of oak, hornbeam and other trees, density of which is at low or medium extent, as well as woodland bushes and steppe xerophytes. The relief is vertically and horizontally is shattered at medium or high extent. This part of the study area is widespread especially on the south-east slopes and low-incline smoothed watershed, and is used in pasturing, planting, gardening, forestry, cutting, ground roads and motorways, etc. The above-mentioned measures are needed to reduce the risk of landslide.

Landscapes of low and much lesser hazard of sliding are small in territory (less than 15\% of total study area). The map in Fig. 4 shows that 8 contours (No. 7, 16, 17, 21, 23, $25,28,29)$ represent the areas of low or very low risk of hazard of sliding. Although the risk of landside is lessened due to the spread of low-incline slopes, the seismicity reaches up to 8 points, while rocks are of high hazard of sliding. In this regard, the area is vulnerable to erosion of river, ravine and gorges origin (Table 3 ).

Table 3. Areas, measured based on the map of landscape- and environmental risks and hazards

\begin{tabular}{|c|c|c|c|c|c|c|}
\hline $\begin{array}{c}\text { Landscape- } \\
\text { and } \\
\text { environmental } \\
\text { types }\end{array}$ & $\begin{array}{c}\text { Number } \\
\text { of } \\
\text { contours }\end{array}$ & Area, $\mathrm{m}^{2}$ & Area, \% & Area, \% & $\begin{array}{c}\text { Intensity } \\
\text { of } \\
\text { landslides }\end{array}$ & $\begin{array}{c}\text { Risk of } \\
\text { landslide } \\
\text { in points }\end{array}$ \\
\hline 1 & 9 & 403721,9626 & 121116,588 & 3,808719 & $0,3-0,5$ & 3 \\
\hline 2 & 5 & 447114,5066 & 134134,35 & 4,218084 & $0,3-0,5$ & 3 \\
\hline 3 & 4 & 275531,5717 & 220425,257 & 2,599369 & $0,8<$ & 5 \\
\hline 4 & 3 & 366759,1383 & 293407,310 & 3,46001 & $0,8<$ & 5 \\
\hline 5 & 2 & 228524,2451 & 685572,73 & 2,1559 & $0,3-0,5$ & 3 \\
\hline 6 & 5 & 128459,8277 & 770758,96 & 1,211891 & $0,6-0,8$ & 4 \\
\hline 7 & 3 & 294656,6776 & 88397,003 & 2,779795 & $0,1-0,3$ & 2 \\
\hline 8 & 2 & 502674,8198 & 402139,855 & 4,742241 & $0,8<$ & 5 \\
\hline 9 & 3 & 458754,2391 & 275252,543 & 4,327893 & $0,6-0,8$ & 4 \\
\hline 10 & 2 & 600683,7308 & 180205,119 & 5,666858 & $0,3-0,5$ & 3 \\
\hline 11 & 1 & 460718,6534 & 276431,192 & 4,346426 & $0,6-0,8$ & 4 \\
\hline 12 & 4 & 512405,2509 & 307443,150 & 4,834038 & $0,6-0,8$ & 4 \\
\hline 13 & 3 & 379231,5856 & 303385,268 & 3,577676 & $0,8<$ & 5 \\
\hline 14 & 1 & 425235,2653 & 255141,159 & 4,011675 & $0,6-0,8$ & 4 \\
\hline
\end{tabular}




\begin{tabular}{|l|l|c|c|c|c|c|}
\hline 15 & 1 & 150574,6216 & 1204596,97 & 1,420523 & $0,8>$ & 5 \\
\hline 16 & 2 & 148934,4501 & 148934,45 & 1,40505 & 0,1 & 1 \\
\hline 17 & 2 & 557686,7885 & 446149,43 & 5,261224 & $0,1-0,8$ & 2 \\
\hline 18 & 4 & 186174,8853 & 558524,65 & 1,756376 & $0,3-0,5$ & 3 \\
\hline 19 & 1 & 99553,24803 & 597319,488 & 0,939187 & $0,6-0,8$ & 4 \\
\hline 20 & 1 & 116724,6676 & 700348,00 & 1,101182 & $0,6-0,8$ & 4 \\
\hline 21 & 3 & 383304,8363 & 114991,450 & 3,616102 & $0,1-0,3$ & 2 \\
\hline 22 & 1 & 1202574,679 & 721544,80 & 11,34511 & $0,6-0,8$ & 4 \\
\hline 23 & 1 & 89312,68918 & 8931,268918 & 0,842577 & $0,1<$ & 1 \\
\hline 24 & 1 & 545600,6958 & 436480,55664 & 5,147204 & $0,8<$ & 5 \\
\hline 25 & 1 & 80973,59801 & 24292,079 & 0,763906 & $0,1-0,3$ & 2 \\
\hline 26 & 1 & 149856,3331 & 44956,899 & 1,413746 & $0,1-0,3$ & 2 \\
\hline
\end{tabular}

\section{Conclusion}

1. The research model, used during this study will allow modelling and assess landscape- and environmental risks and hazards, posed by landslides in young seismic mountain areas of Azerbaijan as well as other young mountain geosystems, shaped during the Alpine folding period. The used model enables to carry out this research as well as similar works in a shorter time based on decipherment of satellite images.

2. In recent years, the study of the sensitivity of landslide areas was widely reported by various aspects in scientific works of researchers (Gritzer et al., 2005; Gupta et al., 1990; Kumtepe et al., 2011; Moreiras, 2005) from European countries, North America and Central America. These researchers have taken into account four or eight factors at best. Unlike these studies, our research proposes new relevant formula and research model. Beside with this, the landscape- and environmental balance of the area was studied. Over related 16 factors were involved in the study. As a result of this, the extent of accuracy and reliability, as well as the possibility of application of the carried out research were increased.

3. The obtained results allow to assess risks and hazards, posed by landslides in the Greater and Lesser Caucasus, as well as Talysh Mountains and mountain areas of Nakhchivan. These results can be used in the implementation of the future regional development programs, landscape planning and also the organization of transport infrastructure in the southeastern part of the Greater Caucasus.

\section{REFERENCES}

[1] Lee, S. (2005): Application of logistic recreation model and its validation for landslide susceptibility mapping using GIS and remote sensing data. - International Journal of remote sensing 26 (7): 1477-1991.

[2] Wang, B.L., Paudel, B., Li, H.Q. (2009): Retrogression characteristics of landslides in fine-grained permafrost soils, Mackenzie Valley, Canada. - Landslides 6(2):121-127.

[3] Mora, S., Yahrson, W. (1994): Macrozonation methodology for landslide hazard determination. - Bulletin of the association of engineering Geology 31(1): 49-58.

[4] Varner, J. D. (1984): Landslide hazard zonation: a review of principles and practice. United Nations Educational Scientific and Cultural Organization (UNESCO) Press, Paris 
[5] Griffiths, J. S., Mather, A. E., Hart, A. B. (2008): Landslide susceptibility in the Rio Aguas catchment. - Quarterly Journal of Engineering Geology and Hydrogeology 35: 917.

[6] Gritzer, L., Andrev, M., Appinal, R. (2005): Assessing landslide Potential Using GIS, Soil Wetness Modeling and Topographic Attributes, Poyette River, Idaho. Geomorphology 37: 149-165.

[7] Gupta, R. P., Joshi, B. C. (1990): Landslide hazard zoning using the GIS approach; A case study from the Ramganga Catchment, Himalayas. - Engineering Geology 28:119131.

[8] Kumtepe, P., Nurlu, J.,Cengiz, T., Sutcu, E. (2011): Heylan Diyarlıl1k haritalarının hazırlanmasında Cografi bilgi Sistemlerinin kullanımı. HKM Geodezi. - Geoinformasyon ve Arazi Yönetim Dergisi 3: 41-46.

[9] Moreiras, S. M. (2005): Landslide susceptibility zonation in the Rio Mendoza Valley, Argentina. - Geomorphology 66: 344-358.

[10] Parise, M. (2001): Landslide mapping techniques and their use in the assessment of the landslide hazard. - Physics and chemistry of the Earth 26(9): 698-703.

[11] Siagian, J. O., Nitihargo, S., Sugalang and Hermovan (2000): Landslide susceptibility Analysis using remote sensing and GIS of the south Cehanjir area, West Java, Indonesia. - Report of International research and Development Cooperation ITT project, 11-28, Japan: 114-121.

[12] Uromeiny, A., Mahdavifar, M. R. (2000): Landslide hazard zonation of the Khorshrostam area, Iran. - The bulletin of Engineering geology and the Environment 58: 207-213.

[13] Saha, A. K., Gupta, R. P., Arora, M. K. (2002): GIS-based landslide hazard zonation in the Bhagirathi (Ganga) Valley, Himalayas. - International Journal of remote sensing 23(2): 357-369.

[14] Carrura, A., Cardinaly, M., Guzetty, F., Reichenbach, P. (1995): GIS technology in mapping landslide hazarde. - GIS system in assessing natural hazards 12: 135-175.

[15] Shulz, W. H. (2007): Landslide susceptibility revealed by LIDAR imagery and historical records, Seattle, Washington. - Engineering Geology 89: 67-87.

[16] Shuster, R. L., Fleming, R.W. (1986): Economic losses and fatalities due to landslides. Environmental \& Engineering Geoscience 23(1): 11-28.

[17] Yalchin, A. (2008): GIS- based landslide susceptibility mapping using analytical hierarchy process and bivariate statistic in Ardesen (Turkey). - Catena 72: 1-12.

[18] Guzrtti, F., Reichenbach, P., Cardinally, M., Gally, M., Ardizzone, F. (2005): Probabilistic landslide hazard assessment at the basin scale. - Geomorphology 72: 272299.

[19] Dai, F. C., Lee, C. F., Li, J., Xu, Z. W. (2001): Assessment of landslide susceptibility on the natural terrain of Lantauisland, Hong Kong. - Environmental Geology 43(3):381-390.

[20] Cevik, E., Topal, T. (2003): GIS-based landslide susceptibility mapping for a problematic segment of the natural gas pipeline, Hendek, Turkey. - Environmental Geology 44: 949962.

[21] Ismayilov, M. J., Mustafayev, N. M. (2012): Features of the landslide development on the southeastern slope of Greater Caucasus. - Transactions of Azerbaijan Geographical Society 12: 95-103. 
[22] Khazaradze, G., Klotz, J. (2003): Short and long-term effect GPS-measured crustal deformation rates along the South-Central Andes. - Journal of Geographical research 108(134): 1-13.

[23] Akgun, A., Bulut, F. (2007): GIS based landslide susceptibility for Arsin-Yomra (Trabzon, North Turkey) region. - Environ. Geology 51: 1377-1387.

[24] Ayalev, L., Yamagichi, H. (2005): The application of GIS-based logistic regression for landslide susceptibility mapping the Kakuda-Jahikomountains, Central Japan. Geomorphology 65: 15-31.

[25] Oh, H. J., Pradhan, B. (2011): Application of neuro-fuzzy model to landslidesusceptibility mapping for shallow-landslides in a tropical hilly area. - Comput. GeosciUK 37(9):1264-1276. 